\title{
BIM AS A CHANGE DRIVER IN PUBLIC ORGANIZATIONS
}

\author{
ANGEL ESTEVE LOPEZ \\ Superior Technical School of Architecture of Madrid, Technical University of Madrid, Spain
}

\begin{abstract}
From the point of view of public entities with responsibilities within the built environment sector, Building Information Modeling (BIM) could bring a new public policy era. This paper proposes an approximation to BIM from the perspective of three different public theories. These perspectives would provide a BIM tentative explanation, in terms of the public values pursued by governments. Public organizations that implement BIM by importing successful cases, without reflecting if the organization is prepared to apply this change, could put their resources at risk. A proactive perspective about BIM implementation, aimed to drive and activate change management, allows organizations to achieve successful BIM goals implementation, while obtaining long-term benefits that go beyond BIM.

Keywords: BIM, public strategy, change management, organization development, digital era governance, shared value.
\end{abstract}

\section{INTRODUCTION}

During the last decade, interest of public entities, governments and international organizations in using BIM to obtain better results in their public policies has grown. They have implemented strategies in order to chase industry sector values: promotion of local industries through clusters, costs reduction, professional and businesses certifications within the AECOM sector, and even knowledge promotion through guidelines, standards and contractual documents. On top of that, private organizations have been more and more interested in BIM implementation as well, especially those companies with commercial activities dependent on the government, such as public procurement and regulation [1].

\section{PUBLIC STRATEGY}

Each of these public entities should pursue their own strategy which should include the abovementioned public values. Whilst some authors define organizational strategy as the search for a unique position [2], others state that strategy lies in organizational commitment with a common vision to create value and sustain itself in the immediate future [3]. The second point of view allows differentiating the private strategy from the public one, based on the value produced and on the nature of the organization's income. These public values could be applied to Moore's strategic model (see Fig. 1).

From the point of view of the fourth industrial revolution - Planen-Bauen 4.0 and UK level 3 - BIM implementation involves a huge social, economic and cultural disruptive change, and organizations need a strategy adapted to a dynamic environment. In such an environment, organizations cannot expect to depend solely on their own direct actions [4]. This means that in the face of uncertain environmental conditions, it seems logical to adopt a reconstructionist [5] strategy where the public organization drives the entire environment in which it operates. And in order to integrate external forces within an adaptable BIM strategy, public managers should understand that, as Porter stated, "operational effectiveness is not strategy."

Within the BIM context, there are operations aimed at increasing the organizational productivity frontier, such as clash detections, LODs, and another instrumental and tactical solutions. Therefore, their leadership model used for operational issues does not necessarily 


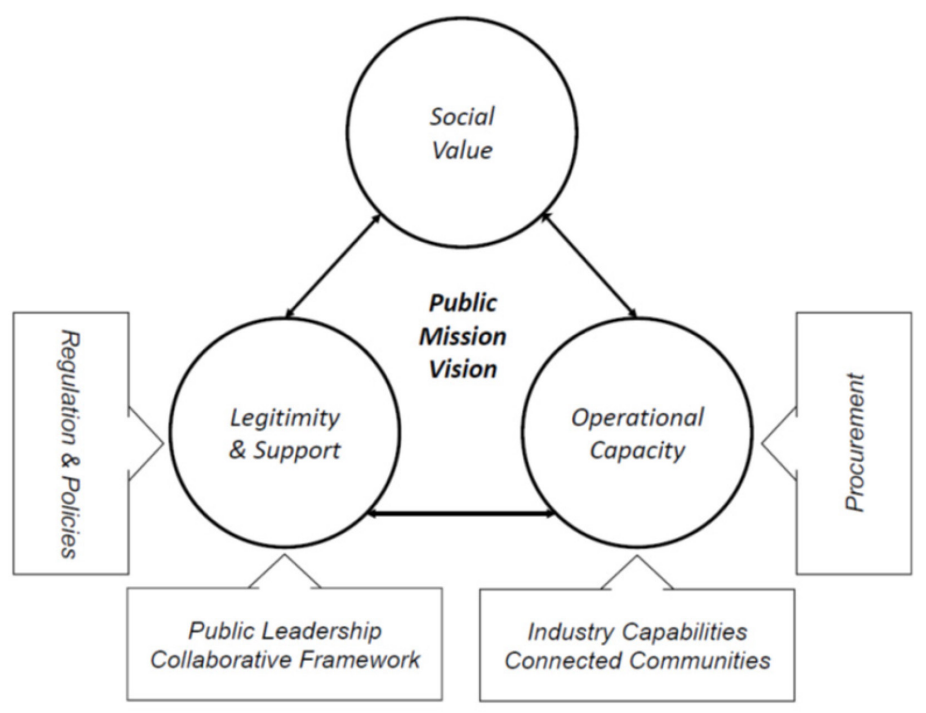

Figure 1: Adam Mathews' strategic framework $(\mathrm{H})$ and World Economic Forum proposals (V) over the Moore's strategic model.

work for change management [6]. This is particularly challenging because the technological arrival of BIM to public organizations may begin at lower levels [7], but deep reflection and adequate change management must go with the introduction of a BIM implementation process that entails an administrative innovation.

But, how would we start such deep reflection? Public organizations [8] shall introduce openness and innovation within its core values in order to survive in a changing environment. Today, however, classic hierarchies are focused on accomplishing matters of routine through expertise and, on the other hand, knowledge-based organizations [9] are focused on solving problems through adaptation. Furthermore, some public organizations still act as closed systems and are incapable of adapting themselves to the knowledge society [10].

As a result, these public organizations are not able to design strategies for an unpredictable and changing environment, and focus its efforts on long-term and non-adaptive strategies [11]. In other cases, governments try to adapt to the new environment through networks in which actors play a soft authority through consensus building. Yet the accountability [12] of these networks is not easy because the responsibility is shared. These are examples in which a strong public organizational culture could move upstream and hold BIM national mandates and strategies back.

\section{A TENTATIVE APPROACH TO BIM THROUGH PUBLIC THEORIES}

Therefore, the deep reflection and organizational change process could start by introducing the following theories (see Table 1) within the public organization strategy:

- $\quad$ organizational development [13];

- a new digital relation [14] between the public organization and citizens through IT changes demanded by the society; and

- a shared value [15] among public and private sectors. 
Table 1: Public theories and their elements.

\begin{tabular}{|l|l|}
\hline Theories & Main elements of these theories \\
\hline \multirow{3}{*}{$\begin{array}{l}\text { Organizational } \\
\text { development }\end{array}$} & Organizational diagnosis \\
\cline { 2 - 2 } & Action research \\
\cline { 2 - 2 } & Change \\
\cline { 2 - 2 } & Complex adaptive system \\
\hline \multirow{4}{*}{$\begin{array}{l}\text { Digital-era } \\
\text { government }\end{array}$} & Organization changes in public agencies \\
\cline { 2 - 2 } & Technology effects in public agencies \\
\cline { 2 - 2 } & Information changes in civil society \\
\cline { 2 - 2 } & Behavior changes in civil society \\
\hline Shared value & Creating and enabling local clusters \\
\cline { 2 - 2 } & Reconceiving products and markets \\
\cline { 2 - 2 } & Redefining value chain \\
\cline { 2 - 2 } & Institutional building \\
\hline
\end{tabular}

\subsection{Organizational development}

Organization development (OD) is a set of theories, ideas and values that explains the change of organizations based on the behavior of the organization. We can consider that OD theories started with the Hawthorne factory studies and the "T-groups". OD theory also includes socio-technological research carried out at the Tavistock Institute. These experiments analyzed the relationships between human and technological factors in work environments.

The conceptual framework for organizational change is based on the three processes (unfreeze, change, and refreeze) enunciated by Kurt Lewis in 1951 to explain how social groups' behavior during a change process. Currently, OD theories are focused on understanding the relationships between organizations and the complexity of the environment in which they operate. Kurt Lewis's theories of change in organizations were enunciated in a less globalized world than the present one and, therefore, with a less complex level of relations. For this reason, in the current context, it seems logical that organizations in the construction sector seek to introduce change and continuous learning within their corporate identity.

BIM adoption is a paradigm shift that takes place in the whole AECOM sector. Public organizations must be aware and should apply a proactive and adaptative change management during the BIM implementation process.

\subsection{Digital-era government}

LSE scholars [14], defined digital-era governance (DEG) as the "whole complex of changes, which have IT and information-handling changes at their center, but which spread much more widely and take place in many more dimensions simultaneously than was the case with previous IT influences." From the point of view of Dunleavy et al. [14], the Internet is changing the public management system in advanced countries. They stated that during the rise of the Internet, its effects were limited to the back office, but it is currently spreading, is taking more dimensions simultaneously and it is significantly modifying the public management. Dunleavy et al. state that the DEG is bringing back many of the effects produced by the previous public management movement, the New Public Management (NPM). 
Through DEG it is possible to explain the new relation among citizens and public organizations. This relationship had changed completely and it is changing the way public organizations are managed as well. According to Dunleavy, DEG is bringing:

- Reintegration by creating new central government processes to do things once instead of many times;

- Needs-based holism creating client-focused structures and implementing end-to-end services that can respond in real time to problems;

- Digitalization of the government business model.

Due to this theory, the information and behavior changes in civil society are driven by changes that are happening in other sectors. IT gives public organizations the chance to adapt their services to new behavioral changes and to provide what society needs in terms of information. DEG's workflow interconnect public agencies and civil society should be permeable to external changes. These external changes are:

- Business sector changes that bring public organization changes;

- Primary IT changes that have technology effects in public agencies;

- Changes in other sectors that bring information changes in civil society and behavior changes in civil society.

The use of BIM and GIS through social media could modify the way in which citizenship and stakeholders received information about public projects. While social media platforms bring different agents together [16], BIM could provide readable building information about the public project through models and graphics, thus increasing the level of accountability. This possibility means that while public agencies as municipalities will gain legitimacy, the public works would gain support from constituents. During the evolution of public projects, organizations are controlled by public accountancy and legal departments. However, during the design and build phases, citizens usually used to have a minor accountability role.

\subsection{Shared value}

The construction industry is facing new global trends which include, among others, "migration into urban areas, climate change and a new global push for infrastructure" [17]. The public sector does not have enough resources to meet new society demands and it needs to bring businesses and NGOs on board in the search of solutions to public policy challenges.

The Shared Value (SV) theory was developed by Michael E. Porter as a way to explain the interconnection of private goals within public challenges. From the point of view of SV, markets are run not just by financial forces, but also by societal forces. For that reason, SV is focused on creating not only financial but also social profits.

In order to build SV, whilst companies should reconceive products and markets, create and enable local clusters and redefine the value chain, governments should provide necessary conditions through "regulations, resources, incentives and convening power" [18]. This new public-private framework, as SV propose, will maximize BIM uses and potentially allow it to evolve within the 4th industrial revolution.

According to Abonyi and Van Slyke [19], governments have a very limited ability to manage the dynamics of the global economy. Its role within a global knowledge society must be the role of the facilitator of these new processes. Therefore, governments should build up the proper environment in which companies can learn and develop skills to enter and compete efficiently in the context of the global value chain. As an economy base in knowledge, companies learn through interaction with other companies, and governments as facilitators 
should develop capabilities as agents for learning, knowledge acquisition, information sharing, coordination and capacity building. Governments must address five considerations in order to implement a proper environment in which the companies of the construction industry could take account of the advantages that the global value chain provides them:

1. Multi-stakeholder partnership;

2. Collaboration learning and mutual adjustment;

3. Institution building;

4. Facilitating networks and clusters;

5. Managing societal adjustment.

\section{CONCLUSION}

The combination of these theories can generate forces that enable the organization to interact ecologically with its surroundings. Internal forces expand the strategic boundary of the organization, while external forces introduce the environment into the organization (see Figs 2 and 3). During the BIM implementation process, the public organization will be forced to
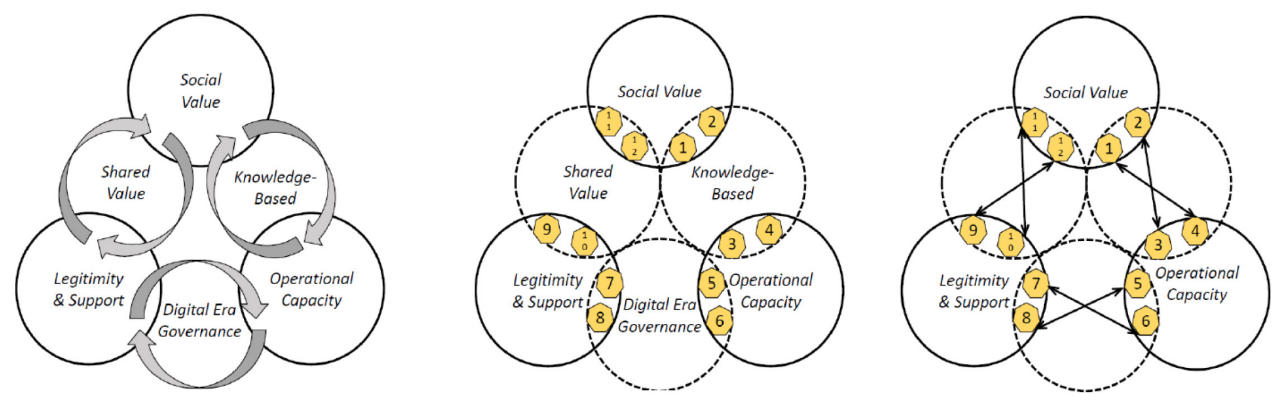

Figure 2: Introduction of shared value, DEG and organizational development paradigms to approach BIM within Moore's strategic for public sector model.
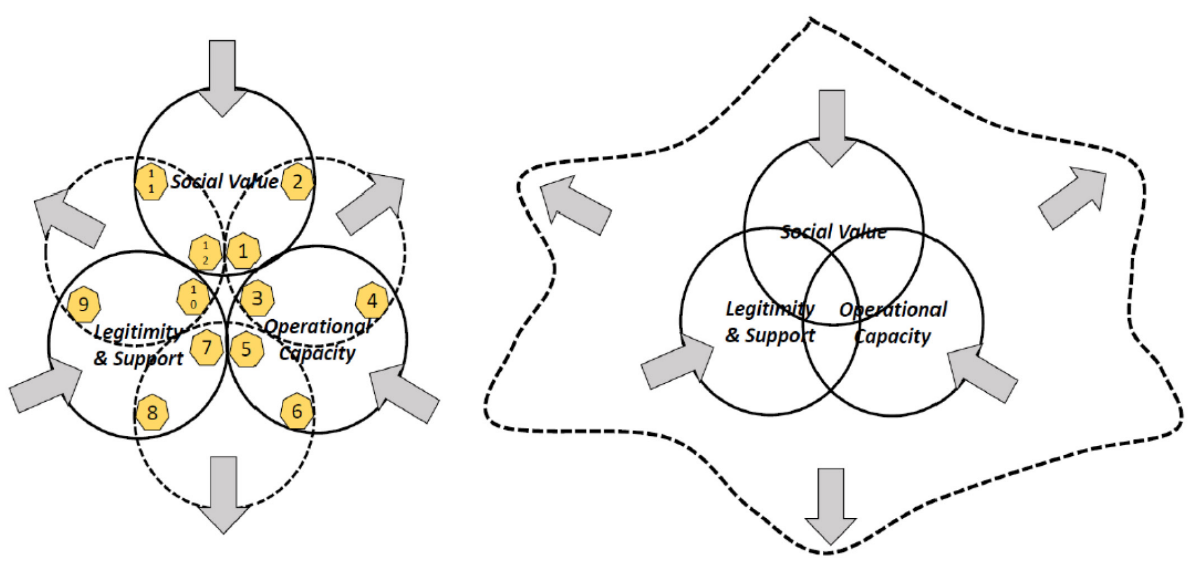

Figure 3: Organization internal and external forces and its new soft organization boundaries that embrace a complex environment. 
open up to its environment, which will require greater internal cohesion. Strategy management should be carried out with guidance. Some authors (e.g. Kaplan and Norton [20]) consider that successful organizations need to measure their performance through a balance scorecard. There are a number of measurement tools to evaluate the BIM maturity level within BIM implementation [21]. The elements that generate internal cohesion and external relations are listed in Table 1, and the key performance indicators should be developed in subsequent studies.

Consequently, the implementation of BIM may bring multiple benefits to the public organization. To start with, by doing so through a knowledge-based and innovative strategy, it would produce a spatial change of the workspace [22]. Public organizations that use BIM within its processes have some spatial features [23] oriented to guarantee the collaborative environment. In these environments, the reliability and improvement of the quality of the information [24] will give a greater decision power to the business lines of the public organization, while the improvement in communication will boost the connection among the base level and the apex level. Because of the change in communication and information, organizational structure would adapt [25] from a pure hierarchical structure to matrix and team structures within the hierarchical public organization structure, growing business lines and reducing the techno-structural level [26]. It is also likely that the maintenance of the change will increase the tasks of the support level of the public organization. Structural changes produced by information and communication changes would reinforce the organization, while opening it to external agents through virtual design teams [27], networks and the global arena [28].

For all of the above, the implementation of BIM within a public organization could open it up to the knowledge society, generating an everlasting benefit.

\section{REFERENCES}

[1] World Economic Forum, prepared in collaboration with the Boston Consulting Group. Industry Agenda, Shaping the future of construction. A breakthrough in mindset and technology, May 2016.

[2] Porter, M.E., What is strategy? Harvard Business Review, Nov.-Dec. 1996.

[3] Moore, M.H., Managing for value: Organizational strategy in for-profit, nonprofit, and governmental organizations. Nonprofit and Voluntary Sector Quarterly, 29(suppl 1), pp. 183-208, 2000.

[4] Emery, F.E. \& Trist, E.L., The causal texture of organizational environments. Human Relations, 18(1), pp. 21-32, 1965.

[5] Chan Kim, W. \& Mauborge, R., How strategy shapes structure. Harvard Business Review, Sep. 2009.

[6] Duck, J.D., Managing change. The art of balancing, Harvard Business Review, 1993.

[7] Jaskyte, K., Predictors of administrative and technological innovations in nonprofit organizations. Public Administration Review, 71(1), pp. 77-86, 2011.

[8] Kettl, D.F. \& Kelman, S., Reflections on 21st Century Government Management, IBM Center for the Business of Government: Washington, DC, 2007.

[9] Nonaka, I. \& Takeuchi, H., The Knowledge-Creating Company: How Japanese Companies Create the Dynamics of Innovation, Oxford University Press, 1995.

[10] Scott, W.R. \& Davis, G.F., Organizations and Organizing: Rational, Natural and Open Systems Perspectives, Routledge, 2015.

[11] O'Donovan, D. \& Rimland Flower, N., The strategic plan is dead. Long live strategy. In today's fast changing world, why freeze your strategic thinking in a five-year plan, 10 Jan., 2013. 
[12] Ketl, D.F., The transformation of governance: Globalization, devolution and the role of government. Public Administration Review, 60(6), pp. 488-497, Nov.-Dec. 2000.

[13] Tschudy, T., An OD map: The essence of organizational development. The NTL Handbook of Organization Development and Change. Principles, Practice and Perspectives, eds B.B. Jones \& M. Brazzel, NTL Institute, 2006.

[14] Dunleavy, P., Margetts, H., Bastow, S. \& Tinkler, J., New public management is dead-long live digital-era governance. Journal of Public Administration Research and Theory, 16(3), pp. 467-494, 2006.

[15] Porter, M.E. \& Kramer, How to fix capitalism and unleash a new wave of growth, Harvard Business School, Jan.-Feb. 2011.

[16] Javaja, P., Suwal, S., Porkka, J., Savisalo, A. \& Kokko, P., Social interaction in urban planning projects, CIB W78 2012: 29th International Conference, Beirut, Lebanon, 2012.

[17] World Economic Forum, prepared in collaboration with the Boston Consulting Group. Industry Agenda, shaping the future of construction. Inspiring innovators redefine the industry, Feb. 2017.

[18] Porter, M.E., Creating shared value: Becoming a movement. Shared Value Leadership Summit, New York, 13 May 2014.

[19] Abonyi \& Van Slyke, Governing on the edges: Globalization of production and the challenge to public administration in the twenty-first century, Public Administration Review, 2010.

[20] Kaplan, R.S. \& Norton, D.P., Measuring the strategic readiness of intangible assets. Harvard Business Review, 82(2), pp. 52-63, 2004.

[21] Dakhil, A., Alshawi, M. \& Underwood, J., BIM Client Maturity: Literature Review, 2015.

[22] Wineman, J.D., Kabo, F.W. \& Davis, G.F., Spatial and social networks in organizational innovations. Environment and Behavior, 41(3), pp. 427-442, May 2009.

[23] Bueno de Silva, W., Institutode Obras Publicas - Governança Colaborativa, 24 Aug. 2016. https://iop.org.br/2016/08/24/gsa-criada-para-ser-referencia/. Accessed on: 7 Dec. 2016.

[24] Bloom, N., Garicano, L., Sadun, R. \& Van Reenen, J., The distinct effects of information technology and communication technology on firm organization. Management Science, 60(12), pp. 2859-2885, 2014.

[25] Stanton, T.H., Moving toward more capable government. A guide to organizational design. Meeting the Challenge of 9/11: Blueprints for More Effective Government, ME Sharpe, p. 25, 2006.

[26] Mintzberg, H., The structuring of organization. A synthesis of the research. Englewood Cliffs, NJ, 1979.

[27] Leavitt, R.E., The virtual design team, designing project organizations as engineers design bridges. Journal of Organization Design, 1(2), pp. 14-41, 2012.

[28] Stone, D., Global public policy, transnational policy communities, and their networks. Policy Studies Journal, 36(1), pp. 19-38, 2008. 